\title{
Metaphors in Bulgarian Political Discourse Since 1989
}

\author{
Ivanka Mavrodieva \\ Department of Library and Information Studies and Cultural Policy, Faculty of Philosophy, Sofia University "St. Kliment \\ Ohridski”, Sofia, Bulgaria \\ Email: mavrodieva@phls.uni-sofia.bg
}

How to cite this paper: Mavrodieva, I. (2020). Metaphors in Bulgarian Political Discourse Since 1989. Advances in Journalism and Communication, 8, 17-27. https://doi.org/10.4236/ajc.2020.82002

Received: March 20, 2020

Accepted: April 19, 2020

Published: April 22, 2020

Copyright (c) 2020 by author(s) and Scientific Research Publishing Inc. This work is licensed under the Creative Commons Attribution International License (CC BY 4.0).

http://creativecommons.org/licenses/by/4.0/

\section{(c) (i) Open Access}

\begin{abstract}
The study of the metaphors used by Bulgarian politicians in speeches, debates, presentations, video clips, posters posted on the Internet clearly shows that they are represented well enough in the media environments. The first hypothesis is that the metaphors used by Bulgarian political orators have changed since 1989 during the transition from socialism to democracy and they have been gradually replaced by new metaphors. The second hypothesis is that metaphors have considerably increased their public influence and they have become a feature of contemporary Bulgarian political discourse. We can also point out two new spheres of manifestations of metaphors at verbal and visual levels of political speech. The figurative language of civil messages and appeals includes metaphors which are more expressive.
\end{abstract}

\section{Keywords}

Metaphor, Bulgarian Political Discourse, Public Influence

\section{Introduction}

After 1989, Bulgaria went through a transformation from socialism to democracy, from a mono-party into a multi-party system as a result of political and social factors. Over the past 30 years, media, technological changes, digitisation and the Internet have been playing a role in changing the political discourse in Bulgaria which is remarkable for its heterogeneity: political speeches, institutional statements, media interviews and discussions, pre-election debates, addresses during demonstrations, press-conferences, presentations, posts on political blogs, personal Facebook walls, virtual political forums, etc. The official political discourse is a function of state institutions and political parties and the oratory of citizens and NGOs has manifestations during protests. Politicians use verbal and 
visual tools in presenting their political programs, proposals, and messages. Bulgarian citizens broadcast appeals, parodies, etc. and they announce their civil requests and messages in front of their virtual communities and audiences. A political discourse is manifested in state institutions, political parties, nongovernmental organisations and it has the following features: communication strategies and tactics, roles of communicators and specific topics. Here it should be noted that state institutions, political parties and nongovernmental organizations have their own system of values and a specific ideology and use specific lexemes, words, and units.

The assumption is that the abstract language from socialist times has gradually been transformed and Bulgarian politicians, state institutions and citizens have started to combine ideological words with figurative language and they have accepted the metaphor as a tool for effectively presenting their ideas and appeals.

\section{Modern Scientific Approaches to the Study of Metaphor}

The study of metaphor dates back more than two millennia, however, in recent years it has been attracting many researchers' attention.

The research in the theory of metaphor began two thousand years ago. Aristotle considers metaphor a figure of speech (Aristotle, 1986). The philosopher insists that reasoning to use metaphors assesses their importance for the description not of "what was" and of "what could be possible in the future with strength of probability or necessity" (Aristotle, 1986: p. 6).

The majority of modern studies of political metaphor is now being carried out at different universities and by different research teams. It is necessary to note, however, that in recent years, research in this area has been carried out on all continents, as it involves experts from different countries. Scientists have received recognition and it has had a significant impact on the development of science in different regions. George Lakoff and Mark Johnsen published a monograph "Metaphor We Live by" (Lakoff \& Johnsen, 2003). According to the two researchers a metaphor is a major cognitive operation and it is not limited to one area of language and the processes of thinking are largely metaphorical. This is what is meant when it is claimed that the conceptual system of a man arranges and defines metaphorically. Metaphors as linguistic expressions are possible precisely because they exist in the conceptual system of a man (Lakoff \& Johnsen, 2003). The basis of cognitive theory of metaphor is the idea that a metaphor is not a linguistic phenomenon and the mental linguistic level only reflects a thinker's processes. Metaphors are not an ornament in language thoughts but only a superficial reflection of conceptual metaphors contained in the conceptual system of humans and structuring their perception, thinking and activity. The cognitive approach applied to the metaphor is characterized by the following features: the metaphor is understood as a basic mental operation, a learning tool and a categorization of the world. In the political sphere, metaphors are charac- 
terized by complexity and a high level of abstraction is necessary to use more simple and concrete images of well-known areas (Lakoff \& Johnsen, 2003).

Over the past three decades scientists from different countries, continents and universities have contributed to the study of metaphors on a theoretical and a research level. Jeffery Scott Mio analyses the relations between a metaphor and politics (Mio, 1997). Christopher Hart focuses on critical discourse analysis of metaphors, creating corpora and a theoretical framework (Hart, 2007, 2008). The following books are the result of a strong and sustained interest in investigating metaphors concerning a policy, politics, politicians, rhetoric, persuasion etc.: "Metaphor and war, again" (Lakoff, 2003), "Metaphorical world politics" (Beer \& Christ'l, 2004), "Politicians and rhetoric". The persuasive power of metaphor" (Charteris-Black, 2004). We are in agreement with definitions and explanations given by the above authors, especially with the positions that verbal metaphors are combined to support the process of understanding the messages and arguments and we will use them as parts of the theoretical background of this study.

A special place among research into metaphor is occupied by the prominent Bulgarian philosopher Isaac Passy' monograph "Metaphor" dedicated to this paradoxical combination of interesting, often contradictory traits and various functions. In the above-mentioned monograph, along with a precise scientific analysis delivered in the author's typical terminological simplicity, there is evaluation of metaphors, called "Divine-human means" (Passy, 1983). The fact that the first edition of this book was as long ago as in 1983 is a sufficient reason to assume that Isaak Passy researched many of the observations ahead of other authors cited too often.

Summarising we can say that the scientific interest in investigating metaphors is on the nature, features, types, manifestations, factors, research methods and communication effects on political attitudes, actions and processes.

\section{Research Questions and Research Design}

The paper studies verbal and visual metaphors used in political discourse in Bulgaria since 1989.

The aim of the study is to find answers to the following research questions:

- What verbal metaphors have been used in Bulgarian political discourse since 1989 ?

- What visual metaphors have been used in Bulgarian political discourse since 1989 ?

- What is the role of metaphors in the messages of politicians in Bulgaria and how do they develop as a result of political, social and media factors?

The study is based on a grounded analysis of political speeches, televised debates, televised interviews, video speeches and video presentations, etc. Next, the focus is placed on metaphors and their specific use in virtual communication, Facebook profiles and video clips published on YouTube. The research includes 
an analysis on communicative channels, media and virtual environments. The corpus includes 100 speeches and debates as well as 100 photos used during the pre-election campaigns. The speeches are selected from speeches delivered by politicians from 20 political parties: the Political Party Citizens for the European Development of Bulgaria, the Bulgarian Socialist Party, the party Alternative for a Bulgarian Revival, the Bulgarian Left, and the Bulgarian Communist Party, Movement 21, the Union of Democratic Forces; the Reformist Block and the Blue Unity, three eco/green parties: the Green Party, the Party of the Greens, and Green Bulgaria; the Movement for Rights and Freedoms (MRF), the Political Party Attack, the Internal Macedonian Odrin Revolutionary Organisation, the Bulgarian National-Patriotic Party, and the Nationalist Party of Bulgaria, the National Movement of Simeon II transformed into National Movement for Stability and Progress, the party Bulgaria without Censorship, the Party Vox Populi and the Bulgarian Agrarian Union.

\section{Verbal Metaphors and Metonyms}

Bulgarian political orators use verbal metaphors and metonyms to emphasise on the main ideas as well as to present positive or negative evaluation.

After 1989, at the beginning of the democratic changes and transformation, Bulgarian politicians use the metaphors home and family trying to present the European Union and a potential membership of Bulgaria positively. The metaphor "The EU is our home" is associated with positive notions, for example, security, protection, building, acceptance, hospitality, construction or reconstruction, creativity, etc. Gradually, during the integration process after 2007 sceptical standpoints are presented by metonyms and metaphors and they are transformed with a negative connotation, for example, "Bulgaria is in the basement of the common European home", "Bulgaria is in the backyard of Europe". The figurative language and in particular metaphors and metonyms negatively present the membership of a particular ethnic group, economic societies when they use different criteria and the focus is not on equal rights and responsibilities but on the origin, territory, negative heritage, etc.

Bulgarian politicians deliver speeches in front of their party, national or international audiences and use the metaphors family and member of family, for example: "We are members of the European family" or "Bulgaria is an integral part of the big European family". The metaphor family is preferred when presenting membership in different geo-political structures and Bulgarian political orators say: Bulgaria is a member of the Balkans family as well as Bulgaria is a member of the big Slavic family. The evaluation is positive when the aim is to persuade the audience of temporary advantages or prospects in political, economic, cultural, and social levels/spheres.

The metaphor road as well as its synonyms highway, freeway, parkway etc. expresses a positive opinion as a part of speeches delivered by Bulgarian politicians after 1989. Political orators combine road with epithets, thus they try to 
emphasis enthusiasm, positive attitudes and emotions, for example: a wide road, a level road, a smooth road, a modern road, etc. Gradually, the Euroscepticism has been enlarged and there are different means of metaphors in connection with the word road in a new context: "Europe prefers two speeds along the integration road", "Bulgaria is not an equal member in the common European road". "Other members of the EU are on the highway, Bulgaria is on a secondary road".

The next group of metaphors used by Bulgarian political orators includes different kinds or various types of transport, vehicles, boat, ship, train, plane, rock$e t$, and the functions of the government are represented by helmsman, captain of ship, ride a train, pilot of airplane and others. These metaphors (a captain, a pilot etc.) incorporate the images of good or failing management of a state, government, an institution or a political party. Political speakers combine metaphors with epithets especially when the goal is to present and describe a party's leaders and statesmen as unable to govern, and the focus is on the lack of experience or fatigue, for example, an inexperienced pilot, novice driver, an elderly driver and others.

The bad results of the state government, economic circumstances and social policy are presented by the metonymy Terminal 2 because the same Bulgarian citizens prefer immigration to different countries. The metaphor one-way ticket is related to the metaphor Terminal 2 and implies scepticism revealing a negative connotation.

Sport metaphors are preferred by Bulgarian political orators when they want to present their evaluation in connection with political life, transformation in a political system and the role of the party leaders. The main focus of metaphorical expansion of sports concepts in the political sphere is associated primarily with events that determine the variety of models. Bulgarian political orators use metaphors from football and boxing very often to present different situations in Bulgarian political processes. The goal of any game is just an exercise, training and leisure and therefore the question arises of how the policy of a game can provide the rights and freedoms of citizens and economic development. The majority of sports metaphors have a negative pragmatic potential determined by the specifics of political orators' aims, the particular political situation and the social sphere. Some metaphors often used by politicians from different political parties presenting an inability to make its independent decision and absence of transparency are: "It is well known who the referee is.", "The match was agreed beforehand", "The match has been decided in the first half.", "They will play in the four rounds", "We know that the match will finish with a knockout", "We want to say that this is not a real political debate, this is a walkover". Political speakers express disdain for smaller parties and for the failures of their opponents; they deride and belittle their opponents through sports metaphors such as: "They will be awarded a red card", "They stand on the bench." "You have been warming up for a very long time, but you are still in the B league." In summary, we can conclude that sports metaphors are associated with the evalua- 
tion of the political sphere. The players, the coach, the referee has a negative pragmatic potential determined by the specifics of the political situation and the social context. The goal of each game is just an exercise, training and leisure and therefore the question arises how exactly politicians take part in political life and if they defend the rights and freedoms of citizens.

The metaphors which include elements from the sphere of medicine are preferred when evaluating politicians negatively, party opponents, complicated political situations and processes. The heart is a central bodily place and it has a significant role and reasonably the metaphors have a connection with this role and emotions. For example, the member of the Bulgarian Socialist Party Georgi Kadiev says that BSP members keep in their heart the flame of the left idea (June 18, 2013).

Medical metaphors or more precisely metonyms are used by Bulgarian political orators when they want to explain the results of activities and processes in a political system principally presenting negative evaluations. It is reasonable to separate two sub-types: different parts of the human body and medical operations on recovery. The figurative model again includes metonyms and epithets thereby strengthening the impression and impact of political speeches.

The first sub-group includes the metonyms and metaphors hand or hands and they have a different meaning in connection with the oratory goal, the political context and the situation. For example, long hand presents the experience of intervention in a party's affairs on part of foreign countries, business corporations, other states, etc. "Dirty hands" is a metaphor for corruption and dishonest transactions. Strong hand is a metaphor presenting a power management or dictatorship. The metaphor operation "clean hands" presents a policeman's activities in connection with criminal penalty.

The second sub-group as pointed out above includes medical operations on recovery. The metaphors used by Bulgarian orators in connection with political life and processes have a connection with polar conditions: health and pain (or suffering). The analysis of metaphorical imagery appears in the contemporary political discourse attributed to various afflictions. For example, during the debates in the National Assembly the following metaphor was used: "Furthermore, here on Monday near the Parliament there are mobile blood donation centres because Bulgaria bled literally and figuratively (June 29, 2013). The leader of the Movement of Rights and Freedoms Lyutvi Mestan uses the metaphor crutches and he suggests giving a chance to political parties and to Bulgaria to go out of the crisis (June, 2013). It is reasonable to conclude that the negative evaluation in connection with the political system, the political elite and the transition from one political party to another for personal reasons, or for a political career is represented by medical metaphors.

The next group includes metaphorical models by which political life is represented by units of different arts, for example: opera, circus, moviel films, theatre, etc. The metaphorical model "performing art" and in particular theatre, opera, movie, circus etc. occupies a significant place in contemporary political 
metaphors. The model presented figuratively is related with the understanding of the performing gaming structure of social interaction, on the one hand. On the other hand, the understanding that life is a performance with actors in the widest sense presents every politician or citizen as a participant on the political and social scene. The first sub-group includes directly named particular events, acts or processes in the contemporary political life in Bulgaria: "This is a circus", "This is a well-known old play", "We have seen this film", "It is an old-fashioned play", "This is amateur theatre", etc. The goal of political orators is to present political life, a particular party event, pre-election campaigns as a pre-prepared act. The negative connotation expresses a lack of transparence, professionalism, a sense of responsibility, statesmanlike thinking. The second sub-group includes metaphors in connection with leaders and again there are polar evaluations presented by combinations with epithets, for example: We know who is a grey director. The producer of this amateur play is well-known from the beginning of the democratic transition, We recognize the political demiurge in this political theatre. In conclusion, we can say that the majority of art metaphors have a negative potential determined by the aims of political orators to describe disappointment with their political opponents, parties and institutions.

Comparing the metaphors from the different groups analysed above we can conclude that political life and civic society events, campaigns, protests, etc. are presented by sport metaphors implying competition, controversy and contest and art metaphors implying the transition from socialism to democracy as a pre-prepared act and process. There are different meanings in sports and art figurative verbal models. The common meaning could be found in two sub-groups, on the one hand, coaches, referees, on the other one, director, and producer. The third sub-group includes players and actors and both of them are presented as participants who do not have opportunities to take active part in the political processes and in the decision-making acts, they watch passively or follow the scenario or plan initiated by other groups: coaches or directors. Sports and art metaphors express a lack of transparency, subordination, alienation and frustration in the processes of political multi-party systems in Bulgaria after 1990, etc.

\section{Visual Metaphors and Metonyms}

The analyses of visual metaphors and metonyms include two sub-parts; in the first part the emphasis is on the positive meaning and the second part focuses on the metaphors used to present negative political models of behavior and negative social manifestations.

The presumption is that the communicative effect is reinforced as a result of the specific "valence" or a mixture of different visual elements and that abstract elements and visual images are mixed in logos or collages.

One of the preferred visual metaphors is a shield used in different variations by the party "Alternative for a Bulgarian Revival", the Political Party "Attack", the Internal Macedonian Odrin Revolutionary Organisation. The shield is included in the logos of political parties, posters, and video clips during election 
campaigns. The shield is well known, and Bulgarian citizens understand it more easily and one of the reasons is that the figurative language associates it with Medieval Bulgarian tsars/kings and the metaphor of a shield contains the meanings of protection, security and statehood.

The metaphor a shield is combined with different visual elements: a map of Bulgaria, the Bulgarian flag, a lion, etc. (see Figure 1). This is a scheme of a visual figurative language which is used to present political ideas and a position in society. On the one hand, the frequency of application of the visual metaphors "shield" and "lion" increases as a result of the election context or of the aim to legitimize the party in the political system as a patriotic one. On the other hand, there is a synergy between verbal and visual metaphors, for example, the Bulgarian National-Patriotic Party and the Nationalist Party of Bulgaria prefer these metaphors.

The party "Bulgaria without Censorship" prefers to combine the sign from proto-Bulgarians with a map of Bulgaria or the Bulgarian flag and there is a synergy between visual metaphors.

The political Party Citizens for European Development of Bulgaria very often mixes the flag of the European Union (EU), stars and a road of a blue colour. The Reformist Block and the Blue Unity also emphasise on the road and the blue colour.

Plants, trees and flowers have become a part of the visual metaphors used by Bulgarian political parties over the last 30 years. The National Movement Simeon the Second includes images of wheat class/wheat stubbles during the campaign for MPs and the National Assembly in 2001. A rose is a mandatory element of posters and videos prepared by PR experts from the Bulgarian Socialist Party. The Movement for Rights and Freedoms (MFR) traditionally during the last 30 years has used an olive branch in posters and video clips which has complex meanings; the metaphor has an association with the Bible, with peace, etc. The Bulgarian Agrarian People's Union prefers a four-leaf clover in different versions (Figure 2).

The metaphors including plant elements are included in posters and video clips, some of them are various types of plants or stylized elements of plants. The three green parties Green Party, the Party of the Greens, and Green Bulgaria independently of each other prefer the green colour. The green parties combine it with different elements, for example, green foliage (see Figure 3).
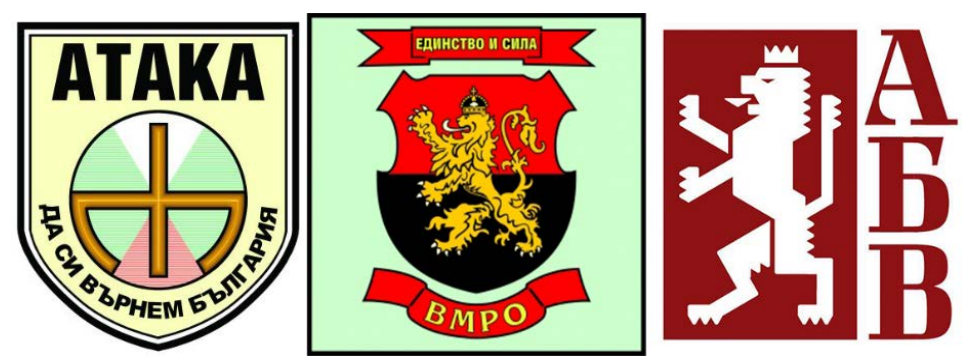

Figure 1. Visual metaphors including "shield" and "lion" in logos of political parties. 

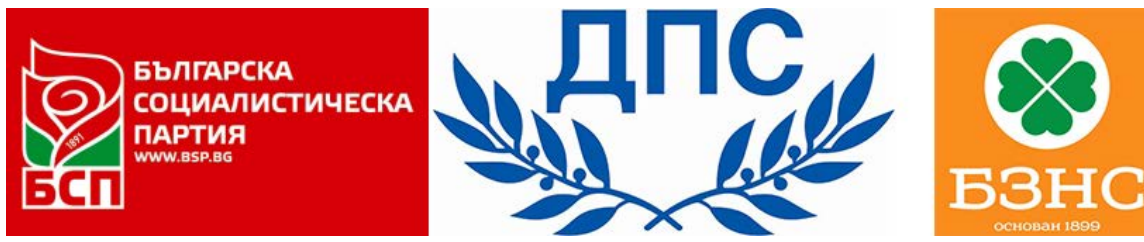

Figure 2. Visual metaphors including plants, trees and flowers in logos of political parties.
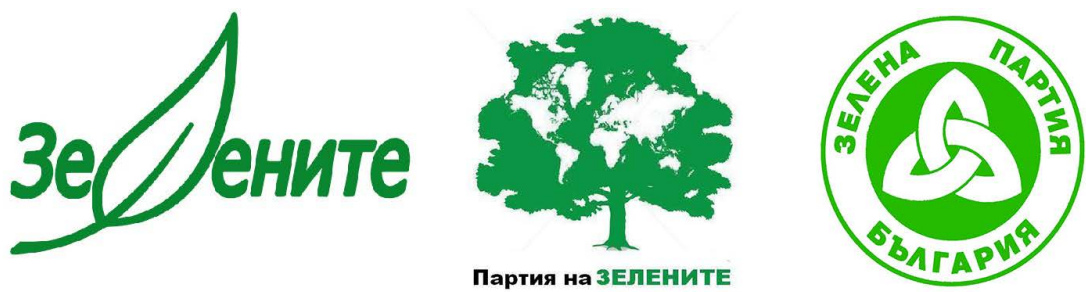

Figure 3. Visual metaphors including green colour, leaves and trees in logos of political parties.

Metaphors including animals are not used very often but their elements are well-known, they have a connection with the national, social and cultural context and they are stylized from an aesthetical and design point of view. It is possible to divide them into two groups. The first one consists of a lion which is an element of the Bulgarian armorial, flags and the suggestion is one of power and statehood.

The second kind of metaphors including animals is relatively new, small political parties present their position towards traditional power, for example, the party called Vox Populi used a cock as a symbol of the awakening of the citizens and different visual options included in posters and videos.

The next version of a visual metaphor includes a road as its main visual element in posters and video clips by the Movement of Freedom and Rights and The Blue Unity. The sense of prosperity is presented clearly because the visual metaphor road is accepted positively.

The most outstanding visual metaphors repeatedly appearing either on posters or online are the logos of the political parties, the national flag and the flag of the $E U$. Each visual element has the power to persuade the audience of the contributions of a different party, Bulgaria or politicians to the EU. Probably visual elements yellow stars and the flag of the $E U$ are a metaphorical approach to present the position that the $\mathrm{EU}$ as an international institution supports Bulgaria and in particular the Political Party Citizens for European Development of Bulgaria.

\section{Conclusion}

We can summarize that the verbal metaphors in Bulgarian political discourse after 1989 are created on the basis of personal or team creativity or as a result of preliminary task assigned by party and political management. It is reasonable to identify some conceptual vectors and one of them is aggressiveness (criminal and military metaphors), competition (sports and military metaphors). The me- 
taphors based on theatre and sports help highlight insincerity in political activity, excessive theatricality and inability to self-decision or subordination and dependency during the political decision-making, negative manifestations in the political life of the country. The metaphorical models described above conceptualize political life in Bulgaria after 1989 presenting the images of political leaders and politicians have undoubtedly affected the public consciousness by strengthening a negative assessment of reality.

Visual metaphors and metonyms have different manifestations, simultaneously more of them are created on the basis of well-known facts, information, arts, etc. Visual metaphors and metonyms bear a universal sense and at the same time have national significance and it is reasonable because the audience possesses the knowledge as part of their cultural heritage and at the same time the contemporary and national circumstances (political polarization and ideological transformations of old parties) insist on including specific elements which are judged about more easily by the members of the particular audience.

In conclusion, we can say that Bulgarian politicians use verbal and visual metaphors and metonyms to present their ideas and that figurative language plays a key role in the political discourse and public space after 1989. The political processes of civic society are presented by orators depending on their ideological beliefs (socialistic, liberal, conservative, democratic, nationalistic, patriotic, eco, etc., party's attitudes (affiliation, loyalty, ambition to be a party's leader), personal prejudices and bias. As a result, the Bulgarian political landscape is described as heterogeneous and dynamic and the social and political structures are represented by notions as well as by verbal and visual metaphors. The role of metaphors in the messages of politicians in Bulgaria has been changed as a result of political, social and media factors and graduately they are used not only strictly officially on the party's websites, advertisement posters, political PR events and rhetorical tribunes. In parallel with these processes verbal and visual metaphors have been used semi-formally and personally in video clips, blogs, virtual forums, social networks and in particular Facebook and Instragram. The manifestations of metaphor have been enlarged in the direction of civic communication during civic protests and activities on social networks and citizens and netizens have started to use metaphors created by themselves as well as parody and periphrasis of official political metaphors, etc. Research on political metaphors could be continued in the future using an interdisciplinary approach or comparing metaphors used by political orators from other countries and studying the common and the specific features of metaphors.

\section{Conflicts of Interest}

The authors declare no conflicts of interest regarding the publication of this paper.

\section{References}

Aristotle (1986). Rhetoric. Sofia: Nauka i Izkustsvo. 
Beer, F. A., \& Christ'l, D. L. (2004). Metaphorical World Politics. (Series: Rhetoric \& Public Affairs). Michigan: Michigan State University Press.

Charteris-Black, J. (2004). Corpus Approaches to Critical Metaphor Analysis. Basingstoke: Palgrave Macmillan. https://doi.org/10.1057/9780230000612

Hart, C. (2007). Critical Discourse Analysis and Conceptualisation: Mental Spaces, Blended Spaces and Discourse Spaces in the British National Party. In C. Hart and D. Lukeš (eds). Cognitive Linguistics in Critical Discourse Analysis: Application and Theory. Newcastle: Cambridge Scholars Publishing, 107-131.

Hart, C. (2008). Critical Discourse Analysis and Metaphor: Toward a Theoretical Framework. Critical Discourse Studies, 5, 91-106. https://doi.org/10.1080/17405900801990058

Lakoff, G. (2003). Metaphor and War, Again. http://www.ugr.es/ jsantana/lies/metaphor and war again.htm

Lakoff, G., \& Johnsen, M. (2003). Metaphors We Live by. London: The University of Chicago Press.

Mio, J. S. (1997). Metaphors and Politics. Metaphor and Symbol, 12, 113-133. https://doi.org/10.1207/s15327868ms1202 2

Passy, I. (1983). Metaphor. Sofia: Nauka and Izkustvo. 